\title{
Enzyme-catalyzed cascade synthesis of hydroxyiminoacetamides
}

\author{
Anamarija Kneževića, $*$, Vladimir Vinkovića ${ }^{\mathrm{a}}$, Nikola Marakovićc ${ }^{\mathrm{b}}$, Goran Šinko ${ }^{\mathrm{b}}$ \\ a Division of Organic Chemistry and Biochemistry, Ruđer Bošković Institute, Bijenička 54, HR-10000 Zagreb, Croatia \\ ${ }^{b}$ Biochemistry and Organic Analytical Chemistry Unit, Institute for Medical Research and Occupational Health, POB 291, HR-10000 Zagreb, Croatia
}

\section{ARTICLE INFO}

\section{Article history:}

Received

Received in revised form

Accepted

Available online

\section{Keywords:}

Amide formation

Chemoenzymatic synthesis

Coupling reagents

Enzyme catalysis

Oxime protecting groups

\section{ABSTRACT}

In order to synthesize $N$-(3-azido-1-phenyl-propyl)-2-hydroxyiminoacetamide, a key compound for the preparation of acetylcholinesterase (AChE) reactivators of the $\mathrm{N}$-substituted 2hydroxyiminoacetamide type, it was necessary to develop a method for forming an amide bond between an oxime ester and an amine. Using Candida antarctica lipase B (CAL-B) in a cascade enzyme-BOP catalyzed reaction, the efficient synthesis of the target hydroxyiminoacetamide was achieved.

2009 Elsevier Ltd. All rights reserved.
Organophosphorus (OP) nerve agents are extremely toxic compounds used as chemical warfare agents in armed conflicts and terrorist attacks ${ }^{1}$ and as pest control agents. ${ }^{2}$ The acute toxicity of these compounds is due to their irreversible inhibition of acetylcholinesterase (AChE; EC 3.1.1.7). ${ }^{3}$ Current therapy in cases of OP nerve agent poisoning includes an antimuscarinic drug (e.g. atropine), an anticonvulsant drug (e.g. diazepam), and an AChE reactivator from the quaternary pyridinium oxime family (2-PAM, trimedoxime, obidoxime, HI-6, Hlö-7). ${ }^{4}$ However, current therapy directed at the reactivation of inhibited AChE is limited to peripheral circulation because commonly used quaternary pyridinium oximes do not cross the blood-brain barrier due to their permanent positive charge. ${ }^{5}$ In order to achieve an efficient reactivation of central nervous system $\mathrm{AChE}$, attempts have been made to develop efficient uncharged reactivators. ${ }^{6}$ Recently, a new series of AChE reactivators, including $N$-substituted 2hydroxyiminoacetamides, was reported. ${ }^{7}$ A few $N$-substituted 2hydroxyiminoacetamides have shown high reactivation potential toward sarin, cyclosarin and VX inhibited AChE. ${ }^{8}$ Because of the significant role of non-bonding interactions between the quaternary pyridinium ring of 2-PAM or HI-6 and the surrounding aromatic amino acids in the AChE active site in the overall stabilization of these compounds, it is reasonable to assume that the introduction of a phenyl ring into the structure of $N$-substituted 2-hydroxyiminoacetamides would help their stabilization and possibly improve the geometry of the oxime group access to phosphylated serine. Thus, the aim of our work was to synthesize several structurally diverse aromatic $N$-substituted 2hydroxyiminoacetamides (2a-c, Figure 1).<smiles></smiles>

Figure 1. Targeted aromatic $N$-substituted 2hydroxyiminoacetamides

The synthesis of key compound 1, [N-(3-azido-1-phenylpropyl)-2-hydroxyiminoacetamide], from which the target molecules 2a-c could be prepared by the well-known copper catalyzed azide-alkyne cycloaddition, ${ }^{9}$ started from readily available cinnamyl alcohol (3) (Scheme 1).<smiles>C=CCC(N)c1ccccc1</smiles>

Scheme 1. Retrosynthetic pathway toward 1 
1-Phenyl-allylamine (4) is prepared from alcohol $\mathbf{3}$ according to a procedure described in the literature ${ }^{10}$ and an azide group was then introduced via a three-step process. The final reaction was the formation of an amide bond between 3-azido-1-phenylpropylamine (5) and ethyl glyoxylate oxime, which was previously described for similar compounds. ${ }^{7}$ However, as in numerous other cases, amide bond formation turned out to represent a significant challenge. ${ }^{11}$

The preparation of 1-phenyl-allylamine (4) from cinnamyl alcohol (3) includes an Overman reaction, which has been welldescribed in the literature. ${ }^{12}$ The hydroxyl group was introduced to Boc protected 1-phenyl-allylamine (6) via hydroborationoxidation using 9-BBN as the hydroboration reagent (Scheme 2).

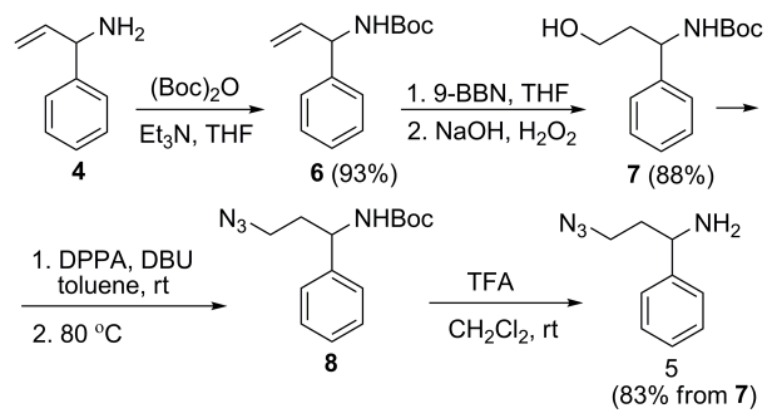

Scheme 2. Synthesis of 3-azido-1-phenyl-propylamine (5).

The hydroxyl group in 7 was replaced with an azide using diphenylphosphoryl azide (DPPA) as the azide source. ${ }^{13}$ The reaction was performed in dry toluene with 1,8diazabicycloundec-7-ene (DBU) as the base. The first step of the reaction, which was performed at room temperature, was the formation of the diphenylphosphate, which can easily be isolated, and the azide salt of DBU. By raising the temperature, nucleophilic substitution of the diphenylphosphate group with azide occurs. The resulting Boc-protected 3-azido-1-phenyl-propylamine (8) was difficult to purify from excess DPPA, so the crude residue was hydrolyzed with trifluoroacetic acid (TFA) in dichloromethane to afford pure 3-azido-1-phenyl-propylamine (5).

The remaining step for the synthesis of $\mathbf{1}$ was assumed to follow the same path as the synthesis of structurally similar reported compounds RS41A and RS194B. ${ }^{7,14}$ The previously described condensation of ethyl glyoxylate with hydroxylamine provided ethyl glyoxylate oxime (9). ${ }^{15}$ The formation of an amide between ethyl glyoxylate oxime and an amine was reported in EtOH at $50{ }^{\circ} \mathrm{C}$. However, in our case, reaction at $50{ }^{\circ} \mathrm{C}$, as well as in boiling $\mathrm{EtOH}$, did not produce the desired product. Addition of $\mathrm{Et}_{3} \mathrm{~N}$ as a base provided a somewhat poor conversion. The search for a solvent and base that would result in a satisfactory conversion of the reactants into the desired product was unsuccessful.

Microwave-assisted reactions, which are known to be very fast and straightforward, also proved unsuccessful. ${ }^{16,17} \mathrm{MW}$ irradiation of $\mathbf{5}$ and $\mathbf{9}$, with or without an additional base, for 30 minutes under solvent-free conditions did not demonstrate enhanced conversion compared to reactions in boiling EtOH. Longer reaction times did not increase the conversion, however new peaks appeared in the HPLC chromatogram indicating the formation of by-products. The results of several attempts to carry out this reaction are presented in Table 1.
Table 1. Testing different conditions for the synthesis of compound $\mathbf{1}$.

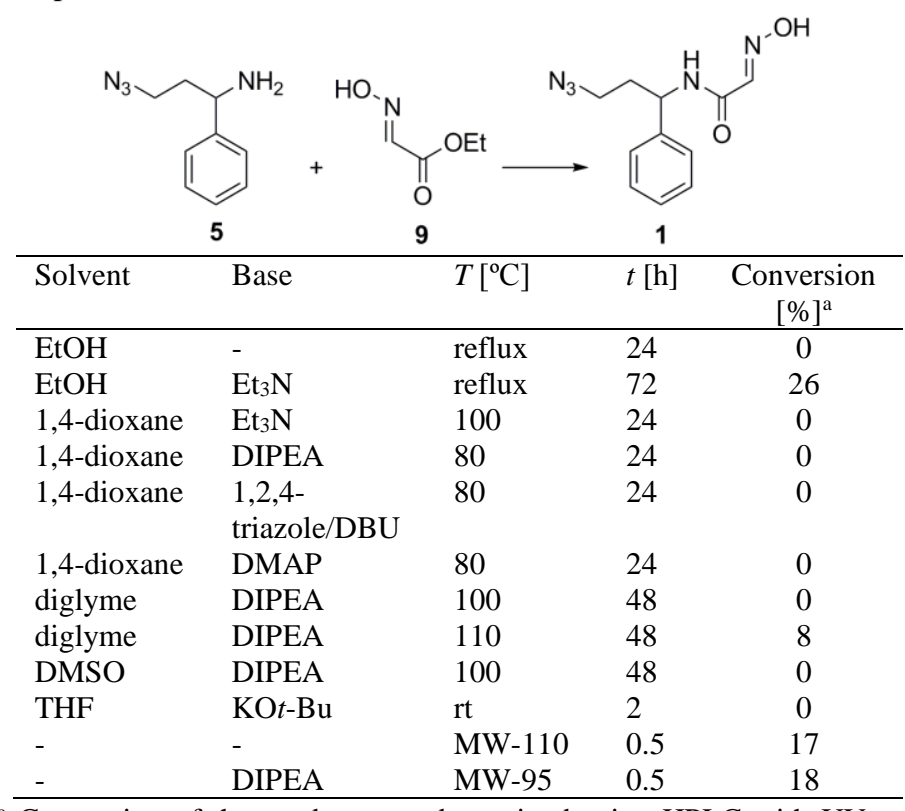

a Conversion of the product was determined using HPLC with UV detection at $220 \mathrm{~nm}$

Bearing in mind our previous experience with Candida antarctica lipase B (CAL-B), ${ }^{10}$ we decided to test this enzyme for our reaction. CAL-B is a very selective biocatalyst in enzymatic resolution of primary amines, as well as an excellent tool for amide bond formation. ${ }^{18}$ However, the test enzymatic reaction of amine 5 and ester 9 using CAL-B did not proceed as desired. The target product was obtained, but in very low yield. We first assumed that these poor results were the consequence of the somewhat ambiguous placement of ester $\mathbf{9}$ in the active site of the enzyme due to its oxime group. In fact, oximes are used as nucleophiles in enzyme-catalyzed oximolysis for the preparation of oxime esters. ${ }^{19}$ Although these activated oxime esters are known to react with amines to give amides, ${ }^{20}$ the success of amide formation depends on the structures of the amines and oxime esters. ${ }^{21}$

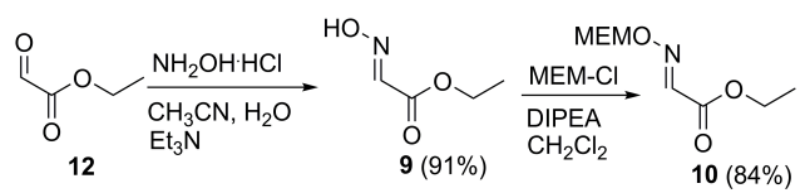

Scheme 3. Synthesis of the MEM-protected oxime 10

Therefore, to exclude the possibility of other side reactions, the oxime group was protected using a 2-methoxyethoxymethyl ether (MEM) protecting group (Scheme 3), starting from ethyl glyoxylate (12). Next, the reaction of the obtained ester 10 with amine 5 was examined. As was the case with unprotected oxime 9, the desired product was obtained in low yield using the classic [EtOH, $N, N$-diisopropylethylamine (DIPEA), reflux for $48 \mathrm{~h}, 16 \%$ yield], as well as the enzymatic approach (Table 2). However, some solid was isolated which was insoluble in methyl tert-butyl ether (MTBE) and diisopropyl ether (DIPE), but was very soluble in dichloromethane. NMR and MS analysis of the solid showed that this substance (13, see Scheme 4) was actually the salt of amine $\mathbf{5}$ and hydrolyzed ester $\mathbf{1 0}$. 
Table 2. Attempts at preparing compound 1 using CAL-B.

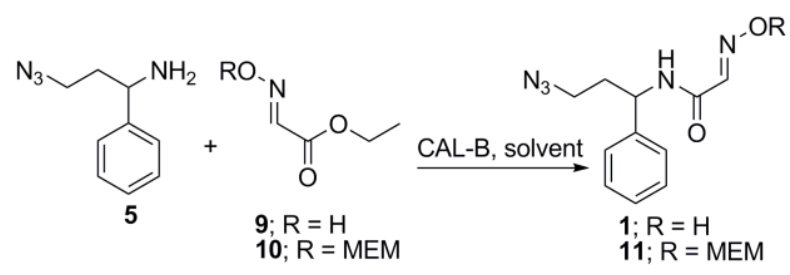

\begin{tabular}{lllll}
\hline Ester & Solvent & $T\left[{ }^{\circ} \mathrm{C}\right]$ & $t[\mathrm{~h}]$ & $\begin{array}{l}\text { Yield of } \\
\mathbf{1} \text { or } \mathbf{1 1}[\%]\end{array}$ \\
\hline $\mathbf{9}$ & DIPE & 40 & 48 & 0 \\
$\mathbf{9}$ & MTBE & 30 & 24 & 9 \\
$\mathbf{9}$ & MTBE & 40 & 24 & 2 \\
$\mathbf{1 0}$ & MTBE & 40 & 72 & 31 \\
$\mathbf{1 0}$ & MTBE $^{\mathrm{a}}$ & 40 & 48 & 23 \\
$\mathbf{1 0}$ & DIPE & 45 & 48 & $0^{\mathrm{b}}$ \\
\hline
\end{tabular}

a $\mathrm{Et}_{3} \mathrm{~N}$ was added to the reaction mixure. ${ }^{22}$ b Salt 13 (see Scheme 4) was isolated from the reaction mixture (96\%).

Considering the results listed in Table 2, it was clear that hydrolysis of ester $\mathbf{1 0}$ catalyzed by the enzyme was faster than the expected amide bond formation reaction. It is generally known that during enzyme-catalyzed aminolysis, even traces of water cause hydrolysis of the acyl donor, which is why such reactions must be performed in dry solvents. ${ }^{18,23}$ DIPE is a solvent which probably contains a sufficient amount of water to prevent amide formation. Hence, salt 13 was isolated in almost quantitative yield (96\%), indicating that under these reaction conditions complete hydrolysis of the MEM-protected ester 10 occurred. Furthermore, ammoniolysis catalyzed by Novozym 435 (CAL-B immobilized on macroporous acrylic resin) has been reported to sometimes be accompanied by unexpected hydrolysis of the ester in spite of the rigorous exclusion of moisture. ${ }^{23}$ It is assumed that these results are the consequence of acrylic carrier adsorption of traces of water flushed out by ammonia. Since we also used Novozym 435, it is reasonable to assume that this problem is also present.

The reaction yield of amide $\mathbf{1 1}$ could be enhanced by using a very large excess of ester that would ensure an ample amount of acyl donor for amide formation. However, ester $\mathbf{1 0}$ is not commercially available and has to be synthesized, so this approach was not suitable. Considering the above-mentioned facts and since we needed amide 1 in racemic form and higher yield if possible, we decided to try an alternative approach.
A large number of coupling reagents for amide bond formation between amines and carboxylic acids have been developed, principally for their use in peptide synthesis. ${ }^{11}$ Benzotriazolyloxytris(dimethylamino)hexafluorophosphate (BOP) was selected due to its ability to work in situ. Typically, the activating agent is added to a 1:1 mixture of the amine and the carboxylic acid. ${ }^{24}$ Accordingly, the isolated salt $\mathbf{1 3}$ was converted into the desired amide $\mathbf{1 1}$ in a BOP-catalyzed reaction (Scheme 4) in satisfactory yield.

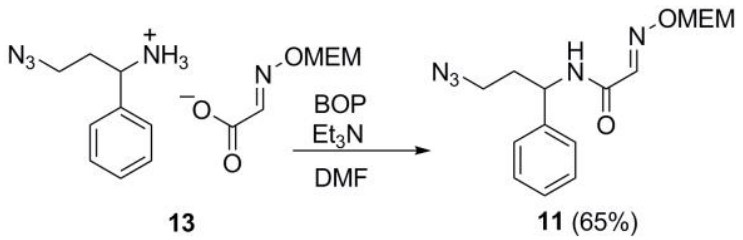

Scheme 4. Formation of amide 11 from salt 13

Considering this reaction proved its potential, we decided to investigate a one-pot cascade enzyme-BOP catalyzed reaction of ester $\mathbf{1 0}$ and amine 5 (Scheme 5). ${ }^{25}$ For reasons mentioned previously, DIPE was selected as the solvent. In this reaction, CAL-B first catalyzed the hydrolysis of ester $\mathbf{1 0}$ which produced salt 13, and then the resulting salt was converted into amide $\mathbf{1 1}$ using the $\mathrm{BOP} / \mathrm{Et}_{3} \mathrm{~N}$ catalyzed reaction. The reaction yield was similar to that obtained when the salt was first isolated from the reaction mixture and then subjected to BOP coupling in DMF. The desired amide $\mathbf{1}$ was now easily obtained from amide $\mathbf{1 1}$ by removing the MEM protecting group under mild reaction conditions using $\mathrm{ZnBr}_{2}{ }^{26,27}$

Herein, we have described the synthesis of hydroxyiminoacetamide $\mathbf{1}$, realized by cascade enzyme-BOP catalyzed reaction. After several unsuccessful attempts in forming an amide bond between ethyl glyoxylate oxime and 3-azido-1phenyl-propylamine, the problem was solved in three steps. The oxime group was protected using 2-methoxyethoxymethyl ether (MEM) protecting group. Obtained MEM-protected oxime ester was hydrolyzed using Candida antarctica lipase B (CAL-B) in organic solvent and then coupled with an amine using BOP coupling reagent in a one-pot cascade reaction. After removing the MEM protecting group under mild conditions, target hydroxyiminoacetamide $\mathbf{1}$ was gained.

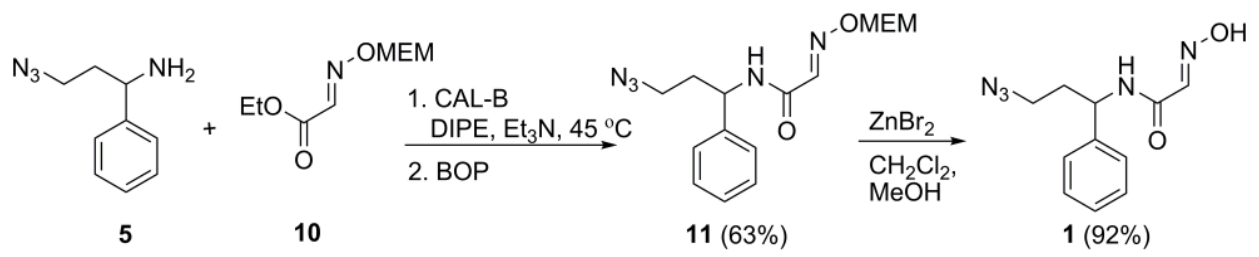

Scheme 5. Synthesis of hydroxyiminoacetamide $\mathbf{1}$ from ester $\mathbf{1 0}$ and amine $\mathbf{5}$.

\section{Acknowledgments}

This study was supported by the Ministry of Science, Education and Sports, Republic of Croatia (grants 098-0982904-2910 and 022-0222148-2889).

\section{References and notes}

1. Yanagisawa, N., Morita, H., Nakajima, T. J. Neurol. Sci. 2006, 249, 76-85.
2. Marrs, T. C. Pharmacol. Ther. 1993, 58, 51-66.

3. a) Quinn, D. M., Chem. Rev. 1987, 87, 955-979; b) Taylor, P., Radić, Z. Annu. Rev. Pharmacol. Toxicol. 1994, 34, 281-320; c) Bosak, A., Katalinić, M., Kovarik, Z. Arh. Hig. Rada. Toksikol. 2011, 62, 175-190.

4. a) Jokanović, M., Stojiljković, M. P. Eur. J. Pharmacol. 2006, 553, 10-17; b) Worek, F., Eyer, P., Aurbek, N., Szinicz, L., Thiermann, H. Toxicol. Appl. Pharmacol. 2007, 219, 226-234.

5. Taylor, P. In: Goodman \& Gilman's The Pharmacological Basis of Therapeutics; Brunton, L. L., Chabner, B. A., Knollman, B. C., Ed.; McGraw-Hill: New York, 2011; 13th ed., pp 239-254. 
6. Mercey, G., Verdelet, T., Renou, J., Kliachyna, M., Baati, R., Nachon, F., Jean, L., Renard, P.-Y. Acc. Chem. Res., 2012, 45, 756-766.

7. Sit, R. K., Radić, Z., Gerardi, V., Zhang, L., Garcia, E., Katalinić, M., Amitai, G., Kovarik, Z., Fokin, V. V., Sharpless, K. B., Taylor, P. J. Biol. Chem. 2011, 286, 19422-19430.

8. Kovarik, Z., Maček, N., Sit, R. K., Radić, Z., Fokin, V. V., Sharpless, K. B., Taylor, P. Chem. Biol. Interact. 2013, 203, 77-80.

9. a) Rostovtsev, V. V., Green, L. G., Fokin, V. V., Sharpless, K. B. Angew. Chem. Int. Ed. 2002, 41, 2596-2599, b) Avti, P. K., Maysinger, D., Kakkar, A. Molecules 2013, 18, 9531-9549.

10. Knežević, A., Landek, G., Dokli, I., Vinković, V. Tetrahedron: Asymmetry 2011, 22, 936-941.

11. a) Montalbetti, C. A. G. N., Falque, V. Tetrahedron 2005, 61 , 10827-10852, b) Valeur, E., Bradley, M. Chem. Soc. Rev. 2009, 38, 606-631, c) Pattabiraman, V. R., Bode, J. W. Nature 2011, 480, 471-479.

12. a) Overman, L. E. J. Am. Chem. Soc. 1974, 96, 597-599; b) Overman, L. E. J. Am. Chem. Soc. 1976, 98, 2901-2910; c) Overman, L. E., Carpenter, N. E. Organic Reactions, Vol. 66, John Wiley \& Sons Inc.: New York, 2005.

13. Thompson, A. S., Grabowski, E. J. J. U.S. Patent 5391 772, 1995.

14. Radić, Z., Sit, R. K., Kovarik, Z., Berend, S., Garcia, E., Zhang, L., Amitai, G., Green, C., Radić, B., Fokin, V. V., Sharpless, K. B. Taylor, P. J. Biol. Chem. 2012, 287, 11798-11809.

15. Kalisiak, J., Ralph, E. C., Zhang, J., Cashman, J. R. J. Med. Chem. 2011, 54, 3319-3330

16. a) Caddick, S. Tetrahedron 1995, 51, 10403-10432; b) Microwave Assisted Organic Synthesis Tierney, J. P., Lidström, P., Ed.; Blackwell Publishing: Oxford, 2005.

17. a) Perreux, L., Loupy, A., Volatron, F. Tetrahedron 2002, 58, 2155-2162; b) Ferroud, C., Godart, M., Ung, S., Borderies, H. Guy, A. Tetrahedron Lett. 2008, 49, 3004-3008.

18. Gotor-Fernández, V., Busto, E., Gotor, V. Adv. Synth. Catal. 2006 $348,797-812$.

19. Gotor, V., Menéndez, E. Synlett 1990, 699-700.

20. a) Fernández, S., Menéndez, E., Gotor V. Synthesis 1991, 713-716; b) Menéndez, E., Gotor, V. Synthesis 1993, 72-74.

21. Lal, S., Snape, T. J. J. Mol. Catal. B: Enzym. 2012, 83, 80-86.

22. Theil, F. Tetrahedron 2000, 56, 2905-2919.

23. van Rantwijk, F., Hacking, M. A. P. J., Sheldon, R. A. Monatsh. Chem. 2000, 131, 549-569.

24. Joullié, M. M., Lassen, K. M. Arkivoc 2010, VIII, 189-250.

25. Enzyme-BOP catalyzed reaction: MEM protected ester 10 (132 $\mathrm{mg}, 0.64 \mathrm{mmol})$ was added to a solution of amine 5 (105 $\mathrm{mg}, 0.60$ $\mathrm{mmol})$ in DIPE $(4 \mathrm{~mL})$ followed by $\mathrm{Et}_{3} \mathrm{~N}(86 \mu \mathrm{L}, 0.61 \mathrm{mmol})$ and immobilized lipase B from $C$. antarctica $(200 \mathrm{mg})$. The mixture was stirred at $45{ }^{\circ} \mathrm{C}$ for $6 \mathrm{~h}$. Next, BOP $(267 \mathrm{mg}, 0.60 \mathrm{mmol})$ was added and the mixture was stirred at the same temperature for another $2 \mathrm{~h}$. The enzyme was filtered off and washed with DIPE and $\mathrm{CH}_{2} \mathrm{Cl}_{2}$. The filtrate was extracted with saturated aqueous $\mathrm{NH}_{4} \mathrm{Cl}$ solution, dried over $\mathrm{Na}_{2} \mathrm{SO}_{4}$, filtered and evaporated under reduced pressure. The crude residue was purified by silica gel column chromatography (hexane-EtOAc, 1:1, $\left.\mathrm{R}_{\mathrm{f}}=0.21\right)$ to give a clear oil $(125 \mathrm{mg}, 63 \%)$.

26. a) Corey, E. J., Gras, J.-L., Ulrich, P. Tetrahedron Lett. 1976, 11, 809-812.; b) Vakalopoulos, A., Hoffmann, H. M. R. Org. Lett. 2001, 3, 2185-2188.

27. MEM-amide deprotection: MEM-protected amide 11 (68 mg, 0.20 mmol) was dissolved in a mixture of $\mathrm{CH}_{2} \mathrm{Cl}_{2}(2 \mathrm{~mL})$ and $\mathrm{MeOH}(0.4$ $\mathrm{mL}$ ). $\mathrm{ZnBr}_{2}$ (oven-dried at $200{ }^{\circ} \mathrm{C}$ overnight) was added $(400 \mathrm{mg}$, $1.8 \mathrm{mmol}$ ) to the solution. The mixture was stirred at $35^{\circ} \mathrm{C}$ until completion of the reaction (monitored by HPLC). The mixture was diluted with $\mathrm{CH}_{2} \mathrm{Cl}_{2}(5 \mathrm{~mL})$ and extracted with saturated aqueous $\mathrm{NaHCO}_{3}$ solution, brine and water, dried over $\mathrm{Na}_{2} \mathrm{SO}_{4}$, filtered, and evaporated under reduced pressure. Amide $\mathbf{1}$ was obtained as a white solid (46 mg, 92\%).

\section{Supplementary Material}

Supplementary material 